\title{
Early outcomes of component separation techniques: an analysis of the Spanish registry of incisional Hernia (EVEREG)
}

\author{
J. A. Pereira-Rodriguez ${ }^{1,2}$ (1) $\cdot$ A. Bravo-Salva, ${ }^{1,2} \cdot$ B. Montcusí-Ventura' ${ }^{1}$ P. Hernández-Granados ${ }^{3}$. \\ V. Rodrigues-Gonçalves ${ }^{4} \cdot M$. López-Cano ${ }^{4,5}$ on behalf of the EVEREG Registry Members
}

Received: 15 April 2021 / Accepted: 21 June 2021 / Published online: 2 July 2021

(c) The Author(s) 2021

\begin{abstract}
Aim To analyze the outcomes of component separation techniques (CST) to treat incisional hernias (IH) in a large multicenter cohort of patients.

Methods All IH repair using CST, registered in EVEREG from July 2012 to December 2019, were included. Data on the pre-operative patient characteristics and comorbidities, IH characteristics, surgical technique, complications, and recurrence were collected. Outcomes between anterior (ACS) and posterior component separation (PCS) techniques were compared. Risk factors for complications and recurrences were analyzed.

Results During the study period, 1536 patients underwent CST ( $45.5 \%$ females) with a median age of 64.0 years and median body mass index (BMI) of $29.7 \mathrm{~kg} / \mathrm{m}^{2}$. ACS was the most common technique (77.7\%). Overall complications were frequent in both ACS and PCS techniques (36.5\%), with a higher frequency of wound infection $(10.6 \% \mathrm{vs.} 7.0 \% ; P=0.05)$ and skin necrosis $(4.4 \%$ vs. $0.1 \% ; P<0.0001)$ with the ACS technique. Main factors leading to major complications were mesh explant (OR 1.72; $P=0.001$ ), previous repair (OR 0.75; $P=0.038$ ), morbid obesity (OR $0.67 ; P=0.015$ ), ASA grade (OR 0.62; $P<0.0001$ ), COPD (OR 0.52; $P<0.0001)$, and longitudinal diameter larger than $10 \mathrm{~cm}$ (OR $0.58 ; P=0.001)$. After a minimum follow-up of 6 months (median 15 months; $N=590), 59(10.0 \%)$ recurrences were diagnosed. Operations performed in a non-specialized unit were significantly associated with recurrences (HR 4.903, CI 1.64-14.65; $P=0.004$ ). Conclusion CST is a complex procedure with a high rate of complications. Both ACS and PCS techniques have similar complication and recurrence rates. Operations performed in a specialized unit have better outcomes.
\end{abstract}

Keywords Incisional hernia $\cdot$ Component separation technique (CST) $\cdot$ Hernia registry $\cdot$ Abdominal wall surgery specialization

J. A. Pereira-Rodriguez jpereira@parcdesalutmar.cat

1 Department of Surgery, Hospital del Mar - Parc de Salut Mar, Passeig Maritim 25-29, 08003 Barcelona, Spain

2 Department of Experimental and Health Sciences, Universitat Pompeu Fabra, Barcelona, Spain

3 Department of Surgery, Hospital Universitario Fundación Alcorcón, Madrid, Spain

4 Abdominal Wall Surgery Unit, Hospital Universitari Vall d'Hebron, Barcelona, Spain

5 Department of Surgery, Universitat Autònoma de Barcelona, Barcelona, Spain

\section{Introduction}

The component separation technique (CST) has become popular in recent years for incisional hernia (IH) repair $[1,2]$. Currently, the following two main CSTs are being used: anterior components separation (ACS) [3] and posterior components separation (PCS) [4]. In both techniques, a mesh is added to reinforce abdominal wall closure and to promote long-term stability [3-5], and both ACS and PCS techniques have proven to be effective [5-7]. Furthermore, in some cases they represent the last chance to achieve a good quality of life for patients who have to modify their lifestyle due to a hernia $[8,9]$.

However, most of the evidence regarding the use of both CSTs is derived from single experiences or high-volume hospitals $[6,10]$. There is a lack of data in a multicenter 
cohort of patients. Real-world evidence (i.e., registries) can provide information from different institutions on routine practice of CST in unselected patients and can answer questions that are more difficult to analyze with other study designs (i.e., randomized studies). The registry of incisional hernia repair (EVEREG) [11] was started in 2012 and was promoted by the Abdominal Wall Chapter of the Spanish Association of Surgeons (AEC), and it represents one of the few registries of these characteristics present across Europe and the rest of the globe.

The aim of this work is to analyze the outcomes of CST comparing the results of anterior vs. posterior techniques in patients registered in the EVEREG, and to identify the factors predicting complications and recurrences of CST.

\section{Methods}

\section{Patients}

EVEREG is an online database accessible on the internet (http://www.evereg.es//). The register of patients is anonymous, and there are 178 participating centers across the country (38\% of 467 National Health System Hospitals). EVEREG is permanently open to all centers that want to participate, and all types of hospitals are included. The registry data structure, committee's approval process, and data collection system have already been described previously [11]. Briefly, it is a prospective database maintained by the surgeons in charge of each center, in which the parameters of the patients, the type of hernia, operations, and complications are collected for each CST performed. The follow-up is performed through clinical control with an appointment one month, 6 months, 1 year, and 2 years after surgery. Patients undergoing a CST technique (anterior or posterior) and registered in the EVEREG from July 2012 to December 2019 were included and analyzed.

\section{Variables}

Demographic variables, including patient's age, gender, and body mass index (BMI), obesity, and overweight following WHO classification [14] were collected. Comorbidities selected were hypertension, diabetes mellitus, chronic obstructive pulmonary disease, chronic renal failure, oncologic history, abdominal aortic aneurysm, and American Society of Anesthesiologists' (ASA) physical status score [12].

IHs were classified according to their location and size according to the EHS classification [15] and complexity [16]. Previous repair and prior use of mesh were identified. Pre-operative optimization with progressive pneumoperitoneum (PPP) or botulinum toxin (BT) was also recorded [17].
Registered surgery characteristics were as follows: clinical setting (i.e., elective or emergency), type of CST (ACS or PCS), concomitant intra-abdominal procedures (i.e., adhesiolysis, bowel resection, and cholecystectomy), panniculectomy, and whether the operation was performed in the Abdominal Wall Unit (AWU). Mesh type, space of mesh placement, and type of fixation were chosen according to the cases and preference of each surgeon.

Perioperative complications, including surgical site occurrences (SSO) (seroma, wound infection, wound hematoma, and skin necrosis), reoperation, and mortality related to surgery during the first postoperative month, were recorded and classified according the ClavienDindo grade [18]. After hospital discharge, patients were followed-up at 1 month, 6 months, and one and two years after surgery. Recurrence was evaluated by clinical examination; and in case of doubt, an ultrasound or computed tomography was indicated.

Exclusion criteria were lack of data for the analysis and absence of follow-up data after surgery. For long-term complications, a minimum 6-month follow-up was considered for the analysis.

The development of the study was performed following the international guidelines of clinical investigation (Ethics Code and Helsinki Declaration) and according to the legal regulations for confidentiality and personal data according to Spanish law. The local ethics committee approved the study protocol (2012/4908/I).

\section{Statistical analysis}

The statistical analysis was performed using the IBM statistical package for the Social Sciences (SPSS) program (IBM Inc., Rochester, MN, USA) version 25 for Windows. Quantitative variables were expressed as mean and standard deviation (SD) and qualitative variables as proportions. To analyze the association between qualitative variables, we used the Chi-squared test $\left(\chi^{2}\right)$ or Fisher's exact test when necessary, as well as Student's t test or the Mann-Whitney $U$ test for quantitative variables. The normality of the distribution of the quantitative variables was verified using the Kolmogorov-Smirnov test. Statistical significance was established at $P<0.05$. The odds ratio (OR) of $\mathrm{IH}$ recurrence was calculated with its $95 \%$ confidence intervals (CI). In the multivariate analysis for complications, the predictive capacity of each variable and its independence from the other predictor variables were analyzed using a binomial logistic regression model by sequentially introducing the variables with an input $\mathrm{F}$ of 0.5. A Cox proportional hazards regression model was used to analyze the risk factors related to recurrence. 


\section{Results}

From July 2012 to December 2019, a total of 11,612 IHs were registered in the EVEREG. A total of 1536 (13.3\%) patients underwent CST and were available for analysis. A total of $1193(77.6 \%)$ patients were treated with an ACS technique and $343(22.4 \%)$ with a PCS technique. All operations were performed by an open approach.
Table 1 shows the characteristics of the patients and the comparison between both techniques. Males represented $54.5 \%$ of the cohort. Median age at time of surgery was 64 years (IQR 55.0-71.0 years), with $31.3 \%$ being older than 70 years. Median BMI was $29.7 \mathrm{~kg} / \mathrm{m}^{2}$ (IQR 26.5-33.5), with a $48.7 \%$ rate of obesity $\left(\mathrm{BMI}>30 \mathrm{~kg} / \mathrm{m}^{2}\right)$. One-third of the cohort $(N=502,32.7 \%)$ had an ASA score III-IV with a higher percentage in ACS patients $(34 \% ; P=0.05)$,

Table 1 Pre-operative demographics of patients and hernia characteristics

\begin{tabular}{|c|c|c|c|c|}
\hline & $N=1536$ & ACS $N=1193$ & $\operatorname{PCS} N=343$ & $P$ \\
\hline \multicolumn{5}{|l|}{ Demographics and comorbidities } \\
\hline Age, years, median (IQR) & $64.0(55.0-71.0)$ & $64.0(54.0-72.0)$ & $64.0(55.0-70.0)$ & 0.972 \\
\hline Age $>70$ years, $N(\%)$ & $480(31.3)$ & $383(32.1)$ & $97(28.3)$ & 0.178 \\
\hline Sex female, $N(\%)$ & $699(45.5)$ & $552(46.3)$ & $147(43.0)$ & 0.282 \\
\hline BMI, kg/m² median (IQR) & $29.7(26.5-33.5)$ & $29.7(26.6-33.5)$ & $29.4(26.3-33.3)$ & 0.399 \\
\hline $\mathrm{BMI}>30 \mathrm{~kg} / \mathrm{m}^{2}$ (obesity), $N(\%)$ & 747 (48.7) & $586(49.2)$ & $161(46.9)$ & 0.452 \\
\hline $\mathrm{BMI}>35 \mathrm{~kg} / \mathrm{m}^{2}$ (severe obesity), $N(\%)$ & $293(19.1)$ & $229(19.2)$ & $64(18.7)$ & 0.808 \\
\hline Alcohol abuse, $N(\%)$ & $204(13.3)$ & $159(13.3)$ & $45(13.1)$ & 0.920 \\
\hline Smoking $N(\%)$ & $403(26.2)$ & $324(27.2)$ & $79(23.0)$ & 0.126 \\
\hline $\mathrm{AHT}, N(\%)$ & $791(51.5)$ & $633(53.3)$ & $158(46.1)$ & 0.022 \\
\hline Diabetes mellitus, $N(\%)$ & $336(21.9)$ & $268(22.5)$ & $68(19.8)$ & 0.297 \\
\hline COPD, $N(\%)$ & $277(18.0)$ & $227(19.8)$ & $50(14.6)$ & 0.059 \\
\hline $\mathrm{CRF}, N=657(\%)$ & $65(9.9)$ & $30(8.9)$ & $35(11.0)$ & 0.368 \\
\hline Immunosuppression $N=524(\%)$ & $79(15.1)$ & $69(15.8)$ & $10(11.4)$ & 0.286 \\
\hline Oncologic history, $N(\%)$ & $411(26.8)$ & $324(27.2)$ & $87(25.4)$ & 0.508 \\
\hline AAA, $N=524(\%)$ & $8(1.5)$ & $6(1.4)$ & $2(2.3)$ & 0.532 \\
\hline ASA III-IV, $N(\%)$ & $502(32.7)$ & $405(34.0)$ & $97(28.4)$ & 0.050 \\
\hline \multicolumn{5}{|l|}{ Hernia characteristics } \\
\hline \multicolumn{5}{|l|}{ Location } \\
\hline Midline, $N(\%)$ & $1349(87.8)$ & $1071(89.8)$ & $278(81.0)$ & $<0.0001$ \\
\hline Trocar, $N(\%)$ & $55(3.6)$ & $29(2.4)$ & $26(7.6)$ & $<0.0001$ \\
\hline Ostomy, $N(\%)$ & $65(4.2)$ & $39(3.3)$ & $26(7.6)$ & $<0.0001$ \\
\hline Other, $N(\%)$ & $71(4.6)$ & $67(5.6)$ & $4(1.2)$ & 0.001 \\
\hline \multicolumn{5}{|l|}{ Defect size* } \\
\hline Area, $\mathrm{cm}^{2}(\mathrm{SD})$ & $176,9(140.7)$ & $187.7(140.2)$ & $148.7(138.1)$ & $<0.0001$ \\
\hline Transverse $>10 \mathrm{~cm},(\mathrm{~W} 3) N(\%)$ & $822(65.9)$ & $642(71.0)$ & $180(52.5)$ & $<0.0001$ \\
\hline Longitudinal $>10 \mathrm{~cm}, N(\%)$ & $965(77.4)$ & $748(82.7)$ & $217(63.3)$ & $<0.0001$ \\
\hline Previous repair, $N(\%)$ & $486(31.6)$ & 357 (29.9) & $214(37.6)$ & 0.007 \\
\hline Previous mesh, $N(\%)$ & $452(93.0)$ & $326(91.3)$ & $126(97.7)$ & 0.015 \\
\hline \multicolumn{5}{|l|}{ Classification of complexity** } \\
\hline Minor, $N(\%)$ & $233(15.2)$ & $175(14.7)$ & $58(16.9)$ & \\
\hline Moderate, $N(\%)$ & $577(37.6)$ & $447(37.5)$ & $130(37.9)$ & \\
\hline Major, $N(\%)$ & $726(47.2)$ & $571(47.9)$ & $155(45.2)$ & \\
\hline \multicolumn{5}{|l|}{ Pre-operative treatment } \\
\hline Pneumoperitoneum, $N(\%)$ & $73(4.8)$ & $60(5.0)$ & $13(3.8)$ & 0.342 \\
\hline Botulinum toxin, $N(\%)$ & $78(5.1)$ & $34(2.8)$ & $44(12.8)$ & $<0.0001$ \\
\hline
\end{tabular}

$B M I$ body mass index, $A H T$ arterial hypertension, $C O P D$ chronic obstructive pulmonary disease, $C R F$ chronic renal failure, $A A A$ abdominal aortic aneurysm, ASA American Society of Anaesthesiologists physical status classification

*EHS classification; **Slater NJ et al. [16] 
and arterial hypertension was most frequent in ACS patients (53.5\%; $P=0.022)$.

The most frequent type of hernia originated in a previous midline laparotomy (87.8\%), with $65.9 \%$ of W3 class according to the EHS classification [16]. A total of $31 \%$ of patients had a previous repair, with mesh in $93.0 \%$ of cases, and $47.2 \%$ of patients were classified as having major complexity [16]. PPP was used as prior therapy in 73 patients (4.8\%) and BT in 78 patients (5.1\%). Hernias treated with ACS were larger, most frequently in the midline, and more frequently received PPP. PCS hernias more frequently underwent a previous repair with mesh and a pre-operative therapy with botulinum toxin.

IH characteristics and comparisons are also displayed in Table 1.

Most of the operations were elective (96.9\%), with a high frequency of a concurrent procedure, and the most frequent was bowel resection (12\%). ACS was the most common technique (77.6\%), and $78.8 \%$ of the operations were performed at an AWU (Table 2).

Types, position, and fixation of prostheses are shown in Table 2. Only eight patients did not receive a mesh, and $24.3 \%$ of cases were repaired using two meshes, more frequently in posterior repair $(P<0.0001)$. When only a mesh was used, the preferred type was reticular polypropylene $(90.1 \%)$, which was less frequently used in PCS (67.3\%). Laminar biosynthetic and biological materials were anecdotally used (0.9\%). In ACS, the preferred position was onlay (51.2\%); and in PCS, the preferred position was sublay (93.6\%). Mesh fixation with a suture was the more frequently used method $(77.1 \%)$, and staplers and glue were more frequently used in the ACS technique than in the PCS technique.

Table 2 Characteristics of the operations and technique of repair

\begin{tabular}{|c|c|c|c|c|}
\hline & $N=1536$ & ACS $N=1193$ & PCS $N=343$ & $P$ \\
\hline \multicolumn{5}{|l|}{ Type of procedure } \\
\hline Elective, $N(\%)$ & $1489(96.9)$ & $1150(96.4)$ & $339(98.8)$ & 0.021 \\
\hline Urgent, $N(\%)$ & $47(3.1)$ & $43(2.8)$ & $4(0.3)$ & \\
\hline Operative time, min, median (IQR) & $150.0(90.0-210.0)$ & $135.0(90.0-200.0)$ & $170.0(120.0-240.0)$ & 0.032 \\
\hline Length of stay, days, median (IQR) & $6.00(4.00-8.00)$ & $6.00(4.00-8.00)$ & $6.00(4.00-8.00)$ & 0.123 \\
\hline $\mathrm{AWU}^{*}, N=821(\%)$ & $647(78.8)$ & $363(74.4)$ & $284(85.3)$ & $<0.0001$ \\
\hline \multicolumn{5}{|l|}{ Associated procedures } \\
\hline Bowel resection, $N(\%)$ & $176(11.5)$ & $145(12.2)$ & $31(9.0)$ & 0.110 \\
\hline Panniculectomy, $N(\%)$ & $122(7.9)$ & $90(7.5)$ & $32(9.3)$ & 0.281 \\
\hline Adhesiolysis, $N(\%)$ & $53(3.5)$ & $46(3.9)$ & $7(2.0)$ & 0.105 \\
\hline Cholecystectomy, $N(\%)$ & $39(2.5)$ & $33(2.8)$ & $6(1.7)$ & 0.291 \\
\hline Mesh removal, $N(\%)$ & $40(2.6)$ & $30(2.5)$ & $10(2.9)$ & 0.681 \\
\hline \multicolumn{5}{|l|}{ Technical details } \\
\hline \multicolumn{5}{|l|}{ Mesh type } \\
\hline No mesh $N(\%)$ & $8(0.5)$ & $7(0.6)$ & $1(0.3)$ & 0.503 \\
\hline Double mesh $N(\%)$ & $372(24.3)$ & $226(19.1)$ & $146(42.7)$ & $<0.0001$ \\
\hline Reticular $N(\%)$ & $1041(90.1)$ & $909(94.7)$ & $132(67.3)$ & $<0.0001$ \\
\hline Composite $N(\%)$ & $104(9.0)$ & $45(4.7)$ & $59(30.1)$ & $<0.0001$ \\
\hline Biosynthetic $N(\%)$ & $5(0.4)$ & $1(0.1)$ & $4(2.0)$ & 0.027 \\
\hline Biologic $N(\%)$ & $6(0.5)$ & $5(0.5)$ & $1(0.5)$ & 0.985 \\
\hline Mesh area, $\mathrm{cm}^{2}(\mathrm{SD})$ & $763.4(653.2)$ & $785.9(673.3)$ & $556.3(350.5)$ & 0.001 \\
\hline \multicolumn{5}{|l|}{ Mesh position } \\
\hline Inlay $N(\%)$ & $30(2.0)$ & $27(2.3)$ & $3(0.9)$ & 0.100 \\
\hline Onlay $N(\%)$ & $615(40.2)$ & $610(51.4)$ & $5(1.5)$ & $<0.0001$ \\
\hline Retromuscular and preperitoneal $N(\%)$ & $779(51.0)$ & $459(38.7)$ & $320(93.6)$ & $<0.0001$ \\
\hline Intraperitoneal $N(\%)$ & $94(6.2)$ & $81(6.8)$ & $13(3.8)$ & 0.40 \\
\hline \multicolumn{5}{|l|}{ Mesh fixation } \\
\hline Staples $N(\%)$ & $250(17.1)$ & $243(21.7)$ & $7(2.0)$ & $<0.0001$ \\
\hline Suture $N(\%)$ & $1137(77.1)$ & $856(75.6)$ & $281(81.9)$ & 0.015 \\
\hline Glue $N(\%)$ & $367(24.2)$ & $312(26.5)$ & $55(16.1)$ & $<0.0001$ \\
\hline
\end{tabular}

*AWU abdominal wall unit 
Complications, including mortality (1.2\%), were frequent after both techniques (36.5\%). The ACS technique was related to a significantly higher incidence of wound infection $(P=0.05)$ and skin necrosis $(P=0.0001)$. Comparison by grade did not show any difference. More complex hernias were correlated with an increased percentage of complications $(P<0.0001)$ (Table 3$)$.

Significant factors leading to any type of postoperative complications in the multivariate analysis are shown in Table 4.

A minimum follow-up of six months (median 14.7 months) was completed in 590 cases $(38.4 \%)$, and the overall recurrence rate was $10.0 \%(N=59)$ without any significant differences on comparing CSTs (ACS 10.8\% vs. PCS $7.5 \% ; P=0.25)$. In univariate analysis, immunosuppression $(\mathrm{OR}=1.25$; CI $0.97-1.61 ; P=0.008)$, emergency repair $(\mathrm{OR}=1.28$; CI $0.94-1.74 ; P=0.007)$, suture repair $(\mathrm{OR}=10.15$; CI $7.95-12.97 ; P=0.003)$, premuscular (onlay) repair (OR 1.05; CI 0.99-1.12), fixation without staples $(\mathrm{OR}=2.35$; CI $1.03-5.35 ; P=0,03)$, no use of glue $(\mathrm{OR}=2.23$; CI $1.10-4.70 ; P=0.02)$, postoperative complications $(\mathrm{OR}=1.98$; CI $1.03-1.16 ; P=0.001)$, seroma $(\mathrm{OR}=1.11 ; \mathrm{CI} 1.01-1.22 ; P=0.005), \mathrm{SSO}(\mathrm{OR}=1.13$; CI $1.02-1.16 ; P=0.004)$, and operation performed in a nonAWU (OR $=2.05$; CI 1.05-4.00; $P=0.035)$ were related to a higher frequency. In the Cox multivariate analysis, nonAWU operation was the only factor significantly associated with recurrences (HR 4.903, CI 1.64-14.65; $P=0.004$ ).
Table 4 Multivariate analysis of risk factors for complications

\begin{tabular}{|c|c|c|c|c|}
\hline & \multirow[t]{2}{*}{$P$} & \multirow[t]{2}{*}{ OR } & \multicolumn{2}{|c|}{$95 \%$ C.I } \\
\hline & & & Low & High \\
\hline $\mathrm{BMI}>35 \mathrm{~kg} / \mathrm{m}^{2}$ & 0.015 & 0.675 & 0.492 & 0.927 \\
\hline COPD & 0.000 & 0.527 & 0.376 & 0.739 \\
\hline Longitudinal diameter $>10 \mathrm{~cm}$ & 0.001 & 0.578 & 0.413 & 0.808 \\
\hline Midline & 0.005 & 0.531 & 0.340 & 0.827 \\
\hline Parastomal & 0.017 & 0.461 & 0.244 & 0.870 \\
\hline Previous repair & 0.038 & 0.754 & 0.578 & 0.985 \\
\hline ASA III-IV & 0.000 & 0.617 & 0.470 & 0.810 \\
\hline Bowel resection & 0.003 & 0.510 & 0.326 & 0.798 \\
\hline Simultaneous hernia repair & 0.020 & 0.460 & 0.239 & 0.885 \\
\hline Premuscular repair & 0.067 & 1.320 & 0.981 & 1.777 \\
\hline No glue & 0.006 & 0.659 & 0.489 & 0.886 \\
\hline Panniculectomy & 0.013 & 0.579 & 0.375 & 0.892 \\
\hline Intra-operative complications & 0.000 & 0.138 & 0.055 & 0.347 \\
\hline
\end{tabular}

\section{Discussion}

To our knowledge, this is one of the largest studies of CST for the treatment of IH. A previous larger study (2245 cases) included all types of ventral hernia (primary and incisional) [19]. The analysis of this series shows that CST is a complex operation, mostly performed in high-risk patients with large major complex hernias, which frequently requires associated procedures and has a high risk of complications.
Table 3 Postoperative 30-day complications

\begin{tabular}{|c|c|c|c|c|}
\hline & $N=1536$ & ACS $N=1193$ & PCS $N=343$ & $P$ \\
\hline Overall, $N(\%)$ & $560(36.5)$ & $421(35.3)$ & $139(40.5)$ & 0.076 \\
\hline Intra-operative $N(\%)$ & $45(2.9)$ & $31(2.6)$ & $14(4.1)$ & 0.151 \\
\hline \multicolumn{5}{|l|}{ Clavien-Dindo grade } \\
\hline Grade I & $210(13.7)$ & $137(11.5)$ & $73(21.3)$ & \\
\hline Grade II & $254(16.5)$ & $207(17.4)$ & $48(14.0)$ & \\
\hline Grade IIIA & $37(2.4)$ & $33(2.8)$ & $4(1.2)$ & \\
\hline Grade IIIB & $29(1.9)$ & $24(2.0)$ & $5(1.4)$ & \\
\hline Grade IV & $11(0.7)$ & $4(0.3)$ & $7(2.0)$ & \\
\hline Grade V & $18(1.2)$ & $16(1.3)$ & $2(0.6)$ & \\
\hline $\mathrm{SSO}, N(\%)$ & $419(27.3)$ & $320(26.8)$ & 99 (28.9) & 0.455 \\
\hline Seroma, $N(\%)$ & $228(14.8)$ & $168(14.1)$ & $60(17.5)$ & 0.117 \\
\hline Wound infection, $N(\%)$ & $150(9.8)$ & $126(10.6)$ & $24(7.0)$ & 0.050 \\
\hline Wound haematoma, $N(\%)$ & $94(6.1)$ & $68(5.7)$ & $26(7.6)$ & 0.200 \\
\hline Skin necrosis, $N(\%)$ & $53(3.5)$ & $52(4.4)$ & $1(0.1)$ & $<0.0001$ \\
\hline Reoperation, $N(\%)$ & $41(2.7)$ & $30(2.5)$ & $11(3.2)$ & 0.483 \\
\hline \multicolumn{5}{|l|}{ Hernia complexity* } \\
\hline Minor, $N(\%)$ & $56(24.0)$ & $39(22.3)$ & $17(29.3)$ & \\
\hline Moderate, $N(\%)$ & $175(30.2)$ & $136(30.4)$ & $39(30.0)$ & \\
\hline Major, $N(\%)$ & $329(45.3)$ & $246(43.1)$ & $83(53.5)$ & \\
\hline
\end{tabular}

*Slater NJ et al. [16] 
Recurrences are comparable to those with the other techniques [12], but when the operation is performed in an elective setting, with a mesh and by an AWU, the rate of recurrences is lower.

In our series, patients undergoing CST were an aged population with a high proportion of obesity $\left(30.3 \mathrm{~kg} / \mathrm{m}^{2}\right.$ average BMI) and other comorbidities; one-third of these patients were classified as ASA III or IV, which has been shown to contribute to worse outcomes. Our population was very similar to that in a previous series [10, 20-22].

It is striking that, of the total registered operations, $13.3 \%$ needed a CST, while in the largest series, the published rate was 3.3\% [19]. Considering the complexity of cases, 34\% of the hernias had a transverse diameter less than $10 \mathrm{~cm}$, reaching $48 \%$ in the PCS cases; thus, the area of the defects was less than that reported in other studies carried out in specialized centers [9]. However, when we analyzed the hernias in relation to their complexity classification [16], 85\% of the patients had criteria of moderate or major complexity. This led us to presume that by using as isolated parameter of complexity, the dimensions of the hernia may be insufficient to predict the need for a CST [10, 20, 23], and other factors related to the hernia or the patients should be considered. Adequate knowledge of the degree of complexity is important to avoid the risk of over-treating low-complex hernias using components separation. Our results suggest that the classification of complexity of Slater et al. [16] is more useful to predict accurately the need for a CST than the diameter of the defect.

Most of the operations were elective (96.9\%), but the operations performed as emergencies presented a high proportion of complications ( $51 \%$ vs. 36\%; $P=0.035$ ), mortality $(12.8 \%$ vs. $0.8 \% ; P=0.014)$, and recurrences $(29.4 v s$. 9.4; $P=0.007)$, and a $51.7 \%$ vs. $20.2 \%(P<0.0001)$ of the operations were performed in a non-specialized unit. When the operations were performed in an AWU, there were fewer complications $(66.7 \%$ vs. $28.6 \% ; P=0.04)$. These data confirm the risks of urgent IH surgery [24] and support the hypothesis that these techniques should be performed, if possible, by specialized surgeons [13] or should be avoided, particularly in higher risk situations, such as emergencies.

Mesh was used in $99 \%$ of the operations, as it has been shown to reduce the recurrence rates [5-7]. A CST without mesh was strongly related to recurrences (OR 10.15); this result, in our opinion, suggests that a non-mesh repair should be avoided in these patients, and if the conditions of surgery preclude the use of mesh, as in emergencies, CST should be postponed.

A high rate of complications, as in a previous series [20, $26,27]$, was observed. In a previous multivariate analysis of the registry [12], CST itself was a risk factor for complications. Overall complications were similar in ACS and PCS techniques. However, the ACS technique had a higher frequency of skin necrosis (related to the technical characteristics) and wound infections. Most of the other risk factors that emerged from our analysis have been previously reported [16, 20-22]. Interestingly, most of them have been compiled by the complexity classification proposed by Slater et al. [16], and in our series, higher complexity was correlated with a higher rate of complications. Our data seem to validate this system of classification to predict the development of complications in terms of the complexity grade.

The main factor related to less recurrences in the multivariate analysis was an operation performed in an AWU, probably due to better selection of patients and technique, for surgeons with a high volume of complex cases and specially involved in abdominal wall reconstruction. The lack of correlation between the BMI and recurrence is noteworthy, since other authors have found an association [16, 21, 22]. An important appreciation is that age did not influence recurrences; thus, performing CST had a similar safety profile in accordance with previous reports [28].

\section{Strengths and limitations}

In our opinion, this study provides a retrospective and comprehensive review of patients undergoing IH repair using CST, and all patients' treatment and follow-up were performed prospectively and registered in the largest database of IH in Spain. The registry itself, as previously shown by registries from other countries [29-31], confirms its usefulness for the collection and analysis of data that can be applied to the treatment of IHs.

Nevertheless, we also acknowledge some weaknesses in our study. First, analysis and patient selection relied exclusively on the EVEREG database, with the inability to study the entire patient data recorded due to the lack of basic elements for analysis or errors in their compilation in some cases. Furthermore, EVEREG is just a sample of reality, because our country does not have a universal registry like other countries, which may lead to biases related to the type of patients and the hospitals that treat them and the data analyzed has not been audited. To improve this, we are involved in a project to audit the data on EVEREG registry (Clinical Trials.gov ID: NCT03899012). Other potential problems are that many patients were excluded or lost to follow-up owing to lack of a complete medical record favoring patients that were more likely to follow-up, and the patient populations might have intrinsic differences and factors predisposing to complex IH that we are not aware of. The low percentatge of long-term follow-up is an issue of our Registry due to its voluntary nature and the lack of incentives. The implementation of reward mechanisms and the involvement of government institutions is necessary to improve this aspect. Finally, our 
research, has the same limitations in the interpretation of its results from other studies based on hernia registries [32].

By contrast, patients operated with minimally invasive surgery were not included. A previous study shows only a $11.7 \%$ of all types of repairs with laparoscopy [11]. Thus, we need a national effort to increase the widespread of minimally invasive techniques to achieve better results. In the future, we must determine if laparoscopy and robotics contributes to reducing the number of complications and recurrences as previously reported [33]. However, minimally invasive repair is very demanding and requires specialized units and surgeons for both laparoscopy and AWR.

\section{Conclusions}

AWR continues to be a challenge. While ACS and PCS are effective methods for managing $\mathrm{IH}$, they are complex surgical techniques with high frequency of complications. Elective mesh repair and treatment in an AWU have better recurrence outcomes, reinforcing the real need to improve the status of our patients, create specific abdominal wall surgery units to treat complex hernias, and perform this skilled technique by dedicated surgeons whenever possible.

Acknowledgements Silvia Martínez and Xavier Masramón. SAIL (Servicio de Asesoría a la Investigación y Logística); Silvia Glahn (B. Braun). We thank LetPub (www.letpub.com) for its linguistic assistance during the preparation of this manuscript.

Funding Open Access funding provided thanks to the CRUE-CSIC agreement with Springer Nature. B. Braun funds the cost of design and hosting of the EVEREG database.

Data availability The datasets analyzed during the current study are not publicly available due to contracts with the hospitals providing to the database.

\section{Declarations}

Conflict of interest JA Pereira, A Bravo, B Montcusí, P. Hernández, V. Rodrigues and M. López-Cano declare no personal conflict of interest.

Ethics approval The local ethics committee approved the study protocol of EVEREG Registry (2012/4908/I).

Human and animal rights This article does not contain any studies with human participants or animals performed by any of the authors.

Informed consent Informed consent was obtained from all individual participants included in the EVEREG Registry.

Consent for publication All authors have approved the manuscript and meet the requirements for authorship.

Open Access This article is licensed under a Creative Commons Attribution 4.0 International License, which permits use, sharing, adaptation, distribution and reproduction in any medium or format, as long as you give appropriate credit to the original author(s) and the source, provide a link to the Creative Commons licence, and indicate if changes were made. The images or other third party material in this article are included in the article's Creative Commons licence, unless indicated otherwise in a credit line to the material. If material is not included in the article's Creative Commons licence and your intended use is not permitted by statutory regulation or exceeds the permitted use, you will need to obtain permission directly from the copyright holder. To view a copy of this licence, visit http://creativecommons. org/licenses/by/4.0/.

\section{References}

1. Deerenberg EB, Timmermans L, Hogerzeil DP, Slieker JC, Eilers PH, Jeekel J, Lange JF (2015) A systematic review of the surgical treatment of large incisional hernia. Hernia 19:89-101

2. Hoffmann H, Köckerling F, Adolf D, Mayer F, Weyhe D, Reinpold W, Fortelny R, Kirchhoff P (2021) Analysis of 4,015 recurrent incisional hernia repairs from the Herniamed registry: risk factors and outcomes. Hernia 25:61-75

3. Ramirez OM, Ruas E, Dellon AL (1990) "Components separation" method for closure of abdominal-wall defects: an anatomic and clinical study. Plast Reconstr Surg 86:519-526

4. Novitsky YW, Elliot HL, Orenstein SB, Rosen MJ (2012) Transversus abdominis muscle release: a novel approach to posterior component separation during complex abdominal wall reconstruction. Am J Surg 204:709-716

5. Razavi SA, Desai KA, Thompson PW, Hart AM, Losken A (2018) The impact of mesh reinforcement with components separation for abdominal wall reconstruction. Am Surg 84:959-962

6. Kokotovic D, Bisgaard T, Helgstrand F (2016) Long-term recurrence and complications associated with elective incisional hernia repair. JAMA 316:1575-1582

7. Sandvall BK, Suver DW, Said HK, Mathes DW, Neligan PC, Dellinger EP, Louie O (2016) Comparison of synthetic and biologic mesh in ventral hernia repair using components separation technique. Ann Plast Surg 76:674-679

8. Aliotta RE, Gatherwright J, Krpata D, Rosenblatt S, Rosen M, Gurunluoglu R (2019) Complex abdominal wall reconstruction, harnessing the power of a specialized multidisciplinary team to improve pain and quality of life. Hernia 23:205-215

9. Blair LJ, Cox TC, Huntington CR, Groene SA, Prasad T, Lincourt AE, Kercher KW, Heniford BT, Augenstein VA (2017) The effect of component separation technique on quality of life (QOL) and surgical outcomes in complex open ventral hernia repair (OVHR). Surg Endosc 31:3539-3546

10. Naran S, Shakir S, Shestak KC, Russavage JM, Nguyen VT (2018) Components separation for abdominal wall reconstruction in the recalcitrant, high-comorbidity patient: a review of 311 singlesurgeon cases (2018). Ann Plast Surg 80:262-267

11. Pereira JA, López-Cano M, Hernández-Granados P, Feliu X, en representación del grupo EVEREG (2016) Initial results of the national registry of incisional Hernia. Cir Esp 94:595-602

12. Pereira JA, Montcusí B, López-Cano M, Hernández-Granados P, Fresno de Prado L, Miembros del registro EVEREG (2018) Risk factors for bad results in the incisional hernia repair. Lessons learned from the National Registry of Incisional Hernia (EVEREG). Cir Esp 96:436-442

13. Pereira JA, Bravo-Salva A, Montcusí B, Pérez-Farre S, Fresno de Prado L, López-Cano M (2019) Incisional hernia recurrence after open elective repair: expertise in abdominal wall surgery matters. BMC Surg 19:103 
14. Obesity: preventing and managing the global epidemic. Report of a WHO consultation (2000) World Health Organ. Tech Rep Ser 894:1-253

15. Muysoms FE, Miserez M, Berrevoet F, Campanelli G, Champault GG, Chelala E, Dietz UA, Eker HH, El Nakadi I, Hauters P, Hidalgo Pascual M, Hoeferlin A, Klinge U, Montgomery A, Simmermacher RK, Simons MP, Smietański M, Sommeling C, Tollens T, Vierendeels T, Kingsnorth A (2009) Classification of primary and incisional abdominal wall hernias. Hernia 13:407-414

16. Slater NJ, Montgomery A, Berrevoet F, Carbonell AM, Chang A, Franklin M, Kercher KW, Lammers BJ, Parra-Davilla E, Roll S, Towfigh S, van Geffen E, Conze J, van Goor H (2014) Criteria for definition of a complex abdominal wall hernia. Hernia 18:7-17

17. Ibarra-Hurtado TR, Nuño-Guzmán CM, Echegaray-Herrar JE, Robles-Vélez E, González-Jaime JJ (2009) Use of botulinum toxin type A before abdominal wall hernia reconstruction. World J Surg 33:2553-2556

18. Dindo D, Demartines N, Clavien PA (2004) Classification of surgical complications: a new proposal with evaluation in a cohort of 6336 patients and results of a survey. Ann Surg 240:205-213

19. Desai NK, Leitman IM, Mills C, Lavarias V, Lucido DL, Karpeh MS (2016) Open repair of large abdominal wall hernias with and without components separation. An analysis from the ACSNSQIP database. Ann Med Surg 7:14-19

20. Ghazi B, Deigni O, Yezhelyev M, Losken A (2011) Current options in the management of complex abdominal wall defects. Ann Plast Surg 66:488-492

21. Kaoutzanis C, Leichtle SW, Mouawad NJ, Welch KB, Lampman RM, Wahl WL, Cleary RK (2015) Risk factors for postoperative wound infections and prolonged hospitalization after ventral/incisional hernia repair. Hernia 19:113-123

22. Owei L, Swendiman RA, Kelz RR, Dempsey DT, Dumon KR (2017) Impact of body mass index on open ventral hernia repair: a retrospective review. Surgery 162:1320-1329

23. Helgstrand F, Rosenberg J, Kehlet H, Jorgensen LN, Bisgaard T (2013) Nationwide prospective study of outcomes after elective incisional hernia repair. J Am Coll Surg 216:217-228

24. Martínez-Serrano MA, Pereira JA, Sancho JJ, López-Cano M, Bombuy E, Hidalgo J, the Study Group of Abdominal Hernia Surgery of the Catalan Society of Surgery (2010) Risk of death after emergency repair of abdominal wall hernias. Still waiting for improvement. Langenbecks Arch Surg 395:551-556
25. Torregrosa-Gallud A, Sancho Muriel J, Bueno-Lledó J, García Pastor J, Iserte-Hernandez J, Bonafé-Diana S, Carreño-Sáenz O, Carbonell-Tatay F (2017) Modified components separation technique: experience treating large, complex ventral hernias at a University Hospital. Hernia 21:601-608

26. Nockolds CL, Hodde JP, Rooney PS (2014) Abdominal wall reconstruction with components separation and mesh reinforcement in complex hernia repair. BMC Surg 14:25

27. Maloney SR, Schlosser KA, Prasad T, Kasten KR, Gersin KS, Colavita PD, Kercher KW, Augenstein VA, Heniford BT (2019) Twelve years of component separation technique in abdominal wall reconstruction. Surgery 166:435-444

28. Docimo S Jr, Bates A, Alteri M, Talamini M, Pryor A, Spaniolas K (2020) Evaluation of the use of component separation in elderly patients: results of a large cohort study with 30-day follow-up. Hernia 24:503-507

29. Israelsson LA, Smedberg S, Montgomery A, Nordin P, Spangen L (2006) Incisional hernia repair in Sweden 2002. Hernia 10:258-261

30. Helgstrand F, Rosenberg J, Bay-Nielsen M, Friis-Andersen H, Wara P, Jorgensen LN, Kehlet H, Bisgaard T (2010) Establishment and initial experiences from the Danish ventral hernia database. Hernia 14:131-135

31. Bisgaard T, Kehlet H, Bay-Nielsen MB, Iversen MG, Wara P, Rosenberg J, Friis-Andersen HF, Jorgensen LN (2009) Nationwide study of early outcomes after incisional hernia repair. Br J Surg 96:1452-1457

32. Schwab R, Dietz UA, Menzel S, Wiegering A (2018) Pitfalls in interpretation of large registry data on hernia repair. Hernia 22(6):947-950. https://doi.org/10.1007/s10029-018-1837-6

33. Balla A, Alarcón I, Morales-Conde S (2020) Minimally invasive component separation technique for large ventral hernia: which is the best choice? A systematic literature review. Surg Endosc 34(1): 14-30

Publisher's Note Springer Nature remains neutral with regard to jurisdictional claims in published maps and institutional affiliations. 